\title{
Cigarette smoking and its association with serum lipid/lipoprotein among Chinese nonagenarians/ centenarians
}

\author{
Zhang Yan-Ling, Zhao Dong-Qing, Huang Chang-Quan and Dong Bi-Rong*
}

\begin{abstract}
Objective: Cigarette smoking had been confirmed as an increased risk for dyslipidemia, but none of the evidence was from long-lived population. In present study, we detected relationship between cigarette smoking habits and serum lipid/lipoprotein (serum Triglyceride (TG), Total cholesterol (TC), Low-density lipoprotein (LDL) and high-density lipoprotein (HDL)) among Chinese Nonagenarians/Centenarian.

Methods: The present study analyzed data from the survey that was conducted on all residents aged 90 years or more in a district, there were 2,311,709 inhabitants in 2005. Unpaired Student's $t$ test, $x^{2}$ test, and multiple logistic regression were used to analyze datas.

Results: The individuals included in the statistical analysis were 216 men and 445 women. Current smokers had lower level of TC ( $4.05 \pm 0.81$ vs. $4.21 \pm 0.87, t=2.403, P=0.017)$ and lower prevalence of hypercholesteremia $\left(9.62 \%\right.$ vs. $\left.15.13 \%, X^{2}=3.018, P=0.049\right)$ than nonsmokers. Unadjusted and adjusted multiple logistic regressions showed that cigarette smoking was not associated with risk for abnormal serum lipid/lipoprotein.

Conclusions: In summary, we found that among Chinese nonagenarians/centenarians, cigarette smoking habits were not associated with increased risk for dyslipidemia, which was different from the association of smoking habits with dyslipidemia in general population.
\end{abstract}

Keywords: Serum lipid/lipoprotein, Cigarette smoking, Nonagenarians/Centenarians

\section{Introduction}

Dyslipidemia was the presence of abnormal levels of lipids in the blood, characterized by an elevation of the concentration of total cholesterol (TC), low-density lipoprotein (LDL), and triglycerides (TG), and a decrease in highdensity lipoprotein cholesterol (HDL) [1,2]. Smoking was a major risk factor for atherosclerotic cerebro- and cardiovascular diseases (CVD) through leading to dyslipidemia [3]. A comprehensive meta-analysis by Craig et al. examined published data from 1966 to 1987 and estimated the excess risk posed by smoking on CVD, with particular emphasis on lipid and lipoprotein involvement [1]. Results of their analysis indicated that compared with non-smokers, cigarettes smokers had significantly higher TC (3\%), TG (9.1\%), and

\footnotetext{
* Correspondence: birongdong@163.com

Department of Geriatrics, West China Hospital, Sichuan University, Guoxuexiang 37, Chengdu, Sichuang province, China 610041
}

LDL (10.4\%), higher (but not significant LDL (1.7\%), and lower concentrations of HDL $(-5.7 \%)$ [1]. In the metaanalysis, a dose-response relationship was found between the number of cigarettes smoked and the change in lipid or lipoprotein variable [1]. The results indicated a progressive increase (\%) as the smoking dosage increased from none to heavy: TC $(0,+0.8,+4.3$ and $+4.5 \%)$, TG $(0,+10.7$, +11.5 and $+18.0 \%)$, LDL $(0,+7.2,+44.4$, and $+39.0 \%)$, and LDL $(0,-1.1,-1.4$ and $+11.0 \%)$. They also reported dose related decreases in HDL $(0,-4.6,-6.3,-8.9 \%)$ [1].

Many physiologic benefits were associated with smoking cessation, including normalization of the lipid and lipoprotein profile. A meta-analysis by Maeda et al. suggested that with smoking cessation an individual could experience an increase in HDL, but other lipid and lipoproteins (TC, LDL, and TG) remained unchanged [4]. Movement toward normalization of HDL could be seen in as little as 17 days and would continue to progress toward normal 
(non-smoking) levels as long as cessation continues. These results had important implications, because they would alter the ratios of HDL, TC, HDL and LDL and could promote clearance of cholesterol from the circulation [4].

The relationship between dyslipidemia and smoking, smoking dosage or smoking cessation had been confirmed by sufficient evidence [5-8]. There was a high smoking rates in China, especially in elderly men, and several millions old people die from smoking-related diseases and dyslipidemia-related diseases in china. Smoking and dyslipidemia synergy to accelerate the death, there might be a difference relationship between smoking and dyslipidemia, clearing the relationship might be important for increasing the proportion of the longevity in population and for improving the health status of the longevity of the elderly. However, all the evidences on association of dyslipidemia with smoking habits were from general population. So it still had been unclear that whether the relationship existed in long-lived subjects or not. In the present study, using data from a sample of Chinese nonagenarians and centenarians, we examined the association between hypertension and dyslipidemia in the long-lived subjects.

\section{Subjects and methods Study subjects}

The methods were reported previously [9-11]. In brief, on the basis of the Dujiangyan (located in Sichuan province, southwest China) 2005 census, a cross-sectional study for age-related diseases was conducted in 870 long-lived subjects ( $>90$ years), which was a part of the Project of Longevity and Aging in Doujiangyan (PLAD). The PLAD aimed to investigate the relationship between environments, lifestyle, genetic, longevity and agerelated diseases. Volunteers were examined by trained professional physicians according to basic health criteria. And the results were filled in the standard form. In this analysis, the subjects, who had no biological specimen for measurement levels serum Lipid/Lipoprotein, or reported the use of drugs affecting the serum lipid/lipoprotein levels, or no information on smoking habits were excluded. The study population ultimately consisted of 661 long-lived subjects. Informed consents were obtained from all participants (as well as their legal proxies). The Research Ethics Committee of the Sichuan University approved the study.

\section{Data collection and measurements}

\section{Measurement of serum lipid/lipoprotein and fasting} blood glucose (FBG)

The methods were reported previously $[10,11]$. Blood samples were collected after an overnight fast (at least $8 \mathrm{~h}$ ) for measurement of serum lipid/lipoprotein. Lipid/lipoprotein levels including serum Triglyceride (TG), TC, Low-density lipoprotein (LDL) and High-density lipoprotein (HDL) were determined by standard laboratory techniques. Cholesterol and triglyceride levels were measured by commercially available enzymatic kits (Roche, Mannheim, Germany) $[12,13]$. FBG was also determined by the standard laboratory techniques $[12,13]$. FBG was assessed using a glucose oxidase assay [14]. Lipid/lipoprotein levels and FBG was performed by a technician in the biochemistry laboratory of Sichuan University. Abnormal levels of serum lipid/ lipoprotein were defined according to the criteria provided by the Chinese Medical Association 2004. Abnormal criteria were: TC $>5.18 \mathrm{mmol} / \mathrm{l}$, TG $>1.7 \mathrm{mmol} / \mathrm{l}$, LDL $>3.37 \mathrm{mmol} / \mathrm{l}$ and $\mathrm{HDL}<1.04 \mathrm{mmol} / \mathrm{l}[15]$.

\section{Cigarette smoking}

Information on smoking habits was inquired using the questionnaire designed according to the previous studies [8,16-18]. Participants was classified the following groups according to the questionnaire [19,20]: 1) nonsmokers: individuals who reported never having a cigarette; 2 ) smokers: individuals who reported smoking every day now and having the habit for more than 6 months; for smokers, the smoking dose was questioned: how many cigarette smoking was taken and the smokers were grouped as follows: light (1-4 cigarette per day), medium (5-9 cigarette per day), heavy (above 10 cigarette per day). 3) With a history of smoking: individuals who had smoking for at least 6 months and including those smoking former and current; 4) smoking cessation: individuals who had quit smoking for at least 6 months; Participants who smoked intermittently (0 or 1 cigarette per day) were not included in the study.

\section{Statistical analysis}

All of the statistical analyses for this study were performed with the SPSS for Windows software package, version11.5 (SPSS Inc, Chicago, Illinois, USA). Serum lipid/lipoprotein levels and prevalence of abnormal levels of serum lipid/ lipoprotein were compared between smokers and nonsmokers, or among groups with different smoking dosage, or with and without history of smoking, or with and without smoking cessation using $X^{2}$ or Fisher's exact test (where an expected cell count was $<5$ ) for categorical variables and unpaired Student's $t$ test for continuous variables. Multiple logistic regression was used to estimate the odds ratio (OR) and 95\% confidence interval (CI) of current smoking and smoking cessation as a function of increased abnormal levels of serum lipid/lipoprotein. $P$ value $<0.05$ was considered to be statistically significant, and all of the $P$ values have two sides.

\section{Results}

\section{Prevalence of abnormal serum lipid/lipoprotein and} smoking habits

Among the 661 participants, mean age was 93.51 years, 69 were centenarians and 445 were women. Ninety percent 
of participants lived in the country side. There were 401 individuals with history of smoking (60.67\%), including 128 (19.36\%) individuals with smoking cessation and 273 (41.30\%) current smokers. The mean of FBG was 4.64 (s. d.:1.45). In those current smokers, 146 (53.48\%), 90 $(32.97 \%)$ and $(13.55 \%)$ were in the light, medium and heavy dosage groups, respectively. Among the sample, men had more current smokers $(64.16 \% \%$ vs. $15.96 \%$, $\left.X^{2}=87.88, \mathrm{P} \leq 0.001\right)$ and more with history of smoking (78.76\% vs. $50.11 \%, \chi^{2}=63.12, \mathrm{P} \leq 0.001$ ) than women.

Among the sample, the means of serum Lipid/Lipoprotein were 4.15 (s.d.:0.85) $\mathrm{mmol} / \mathrm{L}, 1.22$ (s.d.:0.64) $\mathrm{mmol} / \mathrm{L}, 2.28$ (s.d.:0.97) mmol/L, 1.58 (s.d.:0.59) mmol/L for TC, TG, LDL and HDL, respectively. The prevalence of abnormal serum Lipid/Lipoprotein were 75 (11.3\%), 89 (13.5\%), 35 (5.3\%) and 37 (5.6\%) according to TC, TG, LDL and HDL, respectively. (See Tables 1 and 2).

Current smokers had a lower TC serum level and a lower a prevalence of abnormal TC than nonsmokers, but no difference in the other serum lipid/lipoprotein levels and the prevalence abnormal of those

We examined the difference of serum Lipid/Lipoprotein and prevalence of abnormal serum Lipid/Lipoprotein between smokers and nonsmokers. The result showed that current smokers had a lower level of serum TC (4.05 \pm 0.81 vs. $4.21 \pm 0.87, t=2.403, \mathrm{P}=0.017)$, and lower prevalence of abnormal $\mathrm{TC}\left(9.62 \%\right.$ vs. $\left.15.13 \%, \chi^{2}=3.018, \mathrm{P}=0.049\right)$ than nonsmokers. However, none of the difference in the serum TG, LDL and HDL levels was significant between current smokers and nonsmokers (1.21 \pm 0.56 vs. $1.23 \pm 0.69$, $t=0.492, \mathrm{P}=0.623$ for $\mathrm{TG} ; 2.21 \pm 0.55$ vs. $2.28 \pm 0.63$, $t=1.443, \mathrm{P}=0.149$ for LDL; $1.54 \pm 0.62$ vs. $1.60 \pm 0.56$, $t=1.224$., $\mathrm{P}=0.222$ for $\mathrm{HDL})$. None of the difference in prevalence of abnormal TG, LDL and HDL levels was significant between current smokers and nonsmokers $(12.09 \%$ vs. $16.87 \%, \chi^{2}=0.756, \mathrm{P}=0.226$ for $\mathrm{TG} ; 3.80 \%$ vs. $6.88 \%$, $\chi^{2}=2.470, \mathrm{P}=0.080$ for LDL; $7.48 \%$ vs. $4.86 \%, \chi^{2}=1.633$, $\mathrm{P}=0.135$ for HDL). Current smokers showed no significantly higher risk for prevalence of abnormal Lipid/Lipoprotein. (See Tables 1 and 3).

None of difference in serum lipid/lipoprotein levels and the prevalence of abnormal those between subjects with and without smoking history, among groups with different smoking dosage, and between subjects with and without smoking cessation

We further examined the effect of smoking history (including current and former smokers), smoking dosage and smoking cessation on serum Lipid/Lipoprotein levels and the prevalence of abnormal those serum Lipid/Lipoprotein levels. The result showed none difference in serum Lipid/Lipoprotein (including TG, TC, LDL and LDL) and the prevalence of abnormal those (including TG, TC, LDL and LDL) was significant between individuals with and without smoking history, among different smoking dosage and between individuals with and without smoking cessation. There was also no significant difference in risk for the increased prevalence of abnormal those serum Lipid/Lipoprotein levels. (See Tables 2 and 3).

Table 1 Comparing the age, gender, FBG and serum lipid/lipoprotein between subjects with smoking and non-smoking habit, and among groups with different smoking quantity $(n=661)$

\begin{tabular}{|c|c|c|c|c|c|c|c|c|c|}
\hline \multirow[t]{2}{*}{ Characteristics } & \multicolumn{4}{|c|}{ Smoking status } & \multicolumn{5}{|c|}{ Smoking dosage } \\
\hline & Smoker $n=273$ & Non-smoker $n=388$ & $x^{2}$ or $t$ & $P$ value & Light $n=146$ & Medium $n=90$ & Heavy $n=37$ & $X^{2}$ or $F$ & $P$ value \\
\hline Age (years) & $93.37 \pm 3.22$ & $93.62 \pm 3.47$ & 0.944 & 0.346 & $93.52 \pm 3.20$ & $93.23 \pm 3.13$ & $93.11 \pm 3.56$ & 0.362 & 0.697 \\
\hline \multicolumn{10}{|l|}{ Gender $^{a}$} \\
\hline (Male/Female) & $145 / 128$ & $71 / 317$ & 87.88 & $\leq 0.001^{*}$ & $65 / 81$ & $58 / 32$ & $22 / 15$ & 9.567 & $0.008^{*}$ \\
\hline TG (mmol/L) & $1.21 \pm 0.56$ & $1.23 \pm 0.69$ & 0.492 & 0.623 & $1.20 \pm 0.52$ & $1.24 \pm 0.63$ & $1.16 \pm 0.56$ & 0.327 & 0.721 \\
\hline TC (mmol/L) & $4.05 \pm 0.81$ & $4.21 \pm 0.87$ & 2.403 & 0.017 & $4.07 \pm 0.75$ & $4.11 \pm 0.90$ & $3.82 \pm 0.77$ & 1.778 & 0.171 \\
\hline $\mathrm{HDL}(\mathrm{mmol} / \mathrm{L})$ & $1.54 \pm 0.62$ & $1.60 \pm 0.56$ & 1.224 & 0.222 & $1.49 \pm$ & $1.54 \pm$ & $1.52 \pm$ & 1.716 & 0.182 \\
\hline LDL (mmol/L) & $2.21 \pm 0.55$ & $2.28 \pm 0.63$ & 1.443 & 0.149 & $2.23 \pm 0.55$ & $2.23 \pm 0.57$ & $2.06 \pm 0.49$ & 1.535 & 0.217 \\
\hline FBG (mmol/L) & $4.43 \pm 1.58$ & $4.48 \pm 1.36$ & 0.389 & 0.697 & $4.39 \pm 1.54$ & $4.45 \pm 1.53$ & $4.58 \pm 1.82$ & 0.218 & 0.814 \\
\hline \multicolumn{10}{|c|}{ Abnormal Serum Lipid/Lipoprotein } \\
\hline TG & $33 / 240$ & $56 / 332$ & 0.756 & 0.226 & $16 / 130$ & $11 / 79$ & $6 / 31$ & 0.770 & 0.680 \\
\hline $\mathrm{TC}$ & $24 / 249$ & $51 / 337$ & 3.019 & $0.049^{*}$ & $11 / 135$ & $11 / 79$ & $2 / 35$ & 2.138 & 0.350 \\
\hline HDL & $19 / 254$ & $18 / 370$ & 1.633 & 0.135 & $11 / 135$ & $6 / 84$ & $2 / 35$ & 0.224 & 0.894 \\
\hline LDL & $10 / 263$ & $25 / 363$ & 2.470 & 0.080 & $5 / 141$ & $5 / 85$ & $0 / 37$ & 2.344 & 0.310 \\
\hline
\end{tabular}

Comparing the age, gender, FBG and Serum Lipid/Lipoprotein between subjects with smoking and non-smoking habit, and among groups with different smoking quantity, Using $X^{2}$ or Fisher's exact test (where ${ }^{a}$ an expected cell count was $<5$ ) for categorical variables and unpaired Student's $t$ test for continuous variables. In the testing, a $P$ value $<0.05$ was considered to be statistically significant. ${ }^{*} P<0.05 * * P<0.01$. FBG, fasting blood glucose; HDL, high density lipoprotein; LDL, low density lipoprotein; TC: Total cholesterol; TG: Triglyceride. 
Table 2 Comparing the age, gender, FBG and serum lipid/lipoprotein between subjects with history of smoking and non-smoking, and between subjects with different smoking cessation $(n=661)$

\begin{tabular}{|c|c|c|c|c|c|c|c|c|}
\hline \multirow[t]{2}{*}{ Characteristics } & \multicolumn{4}{|c|}{ With history of smoking } & \multicolumn{4}{|c|}{ Smoking cessation } \\
\hline & Yes $n=401$ & No $n=260$ & $x^{2}$ or $t$ & $P$ value & Yes $n=128$ & No $n=273$ & $x^{2}$ or $M D$ & $P$ value \\
\hline Age (years) & $93.41 \pm 3.29$ & $93.67 \pm 3.49$ & 0.980 & 0.327 & $93.50 \pm 3.45$ & $93.37 \pm 3.22$ & $93.62 \pm 3.47$ & 0.944 \\
\hline \multicolumn{9}{|l|}{ Gender $^{a}$} \\
\hline (Male/Female) & $178 / 223$ & $38 / 222$ & 63.120 & $\leq 0.001^{*}$ & $33 / 95$ & $145 / 128$ & $71 / 316$ & 87.88 \\
\hline TG $(m m o l / L)$ & $1.20 \pm 0.63$ & $1.26 \pm 0.66$ & 1.185 & 0.236 & $1.18 \pm 0.75$ & $1.21 \pm 0.56$ & $1.23 \pm 0.69$ & 0.492 \\
\hline TC (mmol/L) & $4.11 \pm 0.83$ & $4.20 \pm 0.88$ & 1.333 & 0.183 & $4.24 \pm 0.86$ & $4.05 \pm 0.81$ & $4.21 \pm 0.87$ & 2.403 \\
\hline $\mathrm{HDL}(\mathrm{mmol} / \mathrm{L})$ & $1.55 \pm 0.55$ & $1.61 \pm 0.64$ & 1.301 & 0.191 & $1.57 \pm 0.37$ & $1.54 \pm 0.62$ & $1.60 \pm 0.56$ & 1.224 \\
\hline LDL (mmol/L) & $2.24 \pm 0.58$ & $2.27 \pm 0.63$ & 0.663 & 0.508 & $2.21 \pm 0.63$ & $2.21 \pm 0.55$ & $2.28 \pm 0.63$ & 1.443 \\
\hline $\mathrm{FBG}(\mathrm{mmol} / \mathrm{L})$ & $4.49 \pm 1.57$ & $4.43 \pm 1.25$ & 0.483 & 0.630 & $4.59 \pm 1.55$ & $4.43 \pm 1.58$ & $4.48 \pm 1.36$ & 0.389 \\
\hline Hypertriglyceridemia & $49 / 352$ & $40 / 220$ & 1.356 & 0.147 & $16 / 112$ & $33 / 240$ & $56 / 332$ & 0.756 \\
\hline Hypercholesteremia & $42 / 359$ & $33 / 227$ & 0.772 & 0.360 & $18 / 110$ & $24 / 249$ & $51 / 337$ & 3.019 \\
\hline Lower HDL & $25 / 376$ & $12 / 248$ & 0.782 & 0.240 & $6 / 122$ & $19 / 254$ & $18 / 370$ & 1.633 \\
\hline Higher LDL & 20/381 & $15 / 345$ & 0.192 & 0.363 & 10/118 & $10 / 263$ & $25 / 363$ & 2.470 \\
\hline
\end{tabular}

* $P<0.05 * * P<0.01$ vs. Using $X^{2}$ or Fisher's exact test (where an expected cell count was $<5$ ) for categorical variables and unpaired Student's $t$ test for continuous variables. In the testing, a $P$ value $<0.05$ was considered to be statistically significant. FBG, fasting blood glucose; HDL, high density lipoprotein; LDL, low density lipoprotein; TC: Total cholesterol; TG: Triglyceride.

\section{Discussion}

This study evaluated the effect of smoking habits (including current smoker, smoking history, smoking dosage and smoking cessation) on serum Lipid/Lipoprotein (including TG, TC, LDL and HDL). Current smoker had lower serum TC and lower risk for abnormal serum TC. The serum lower serum TC and lower risk for abnormal serum TC did not exist in individuals with smoking history, heavy smoking dosage and smoking cessation. Smoking habits did not have effect on serum TG, LDL and HDL.

Table 3 Effect of smoking and smoking cessationon abnormal serum lipid/lipoprotein in long-lived subjects

\begin{tabular}{|c|c|c|c|c|c|c|}
\hline \multirow[t]{2}{*}{ Characteristics } & \multicolumn{3}{|c|}{ Smoking } & \multicolumn{3}{|c|}{ Smoking cessation } \\
\hline & With/without (273/388) & OR & $95 \% \mathrm{Cl}$ & With/without (273/128) & OR & $95 \% \mathrm{Cl}$ \\
\hline \multicolumn{7}{|l|}{ TC } \\
\hline NO. of Risk/Case & $33 / 56$ & & & $18 / 24$ & & \\
\hline Unadjusted & & 1.321 & $0.677-2.541$ & & 1.295 & $0.522-3.212$ \\
\hline Adjusted & & 1.497 & $0.734-3.053$ & & 1.329 & $0.517-3.414$ \\
\hline \multicolumn{7}{|l|}{ TG } \\
\hline NO. of Risk/Case & $24 / 51$ & & & $16 / 33$ & & \\
\hline Unadjusted & & 1.126 & $0.693-1.830$ & & 0.876 & $0.442-1.738$ \\
\hline Adjusted & & 1.074 & $0.639-1.083$ & & 0.895 & $0.438-1.827$ \\
\hline \multicolumn{7}{|l|}{ LDL } \\
\hline NO. of Risk/Case & $10 / 25$ & & & $6 / 19$ & & \\
\hline Unadjusted & & 1.310 & $0.503-3.459$ & & 1.804 & $0.519-6.267$ \\
\hline Adjusted & & 0.957 & $0.343-2.670$ & & 1.564 & $0.430-5.685$ \\
\hline \multicolumn{7}{|l|}{$\mathrm{HDL}$} \\
\hline NO. of Risk/Case & $19 / 18$ & & & $10 / 10$ & & \\
\hline Unadjusted & & 0.671 & $0.341-1.313$ & & 0.709 & $0.274-1.832$ \\
\hline Adjusted & & 0.732 & $0.355-1.508$ & & 0.753 & $0.283-2.003$ \\
\hline
\end{tabular}

$(\mathrm{n}=661)$.

OR, odds ratio. Unadjusted: Wald Chi-square test with $\mathrm{df}=1$ was used; Adjusted multiple logistic regression was used to adjust for age, gender, FBG. FBG, fasting blood glucose; HDL, high density lipoprotein; LDL, low density lipoprotein; TC: Total cholesterol; TG: Triglyceride. 
In the present study, the result showed current smokers had lower level of TC and lower prevalence of abnormal TC [21-27]. This indicated that current smoking was associated with low serum TC levels, but none of difference in TC levels and prevalence of abnormal TC was significant difference among individuals with different smoking dosage. All of these results indicated that effect of smoking habits on serum TC was independent on smoking dosage.

Previous studies confirmed that in general population, current smoking increased TC levels and prevalence of abnormal TC, heavy smoking was associated with increased $\mathrm{TC}$ and higher risk for abnormal TC, and smoking cessation was associated with decreased TC and decreased risk for abnormal TC. Our result showed that the relationship between smoking habits and serum TC in long-lived subjects was different that in general population. This was an interesting finding. Mechanisms of difference could be explained by the following. In Chinese, mean life span was 77 years in 2011, in the present study, the all participants were all above 90 years. In the elderly, with aging, mortality rate increased. Smoking habits led to high TC in general adult. Smoking habits and hypercholesteremia were both definitive risk for cerebrovascular disease. Smoking habits and hypercholesteremia were also the confirmed risk for dementia, depression, disability and so on, all of these increased mortality rate in the elderly above 65 years $[28,29]$. The high mortality in the elderly could remove those with hypercholesteremia, which was caused by current smoking. This mean those with both habits of current smoking and hypercholesteremia were more possibly removed by the high mortality in the elderly, and left individuals with lower TC in current smokers. This led to a lower TC level in current smokers, compared nonsmokers. This only a reasonable inference, which should be further confirmed using prospective cohort study.

To the best of our knowledge, this was the first research which focused on the association of smoking habits (including current smokers, with history of smokers, with different smoking dosage and smoking cessation) and serum Lipid/ Lipoprotein among Nonagenarians/Centenarians. This study showed there was different in the association. Previous studies showed that current smoking and heavy dosage of smoking were both associated with increased TG, TC and LDL, and with decreased HDL. Smoking cessation could reverse the effect of smoking on serum Lipid/Lipoprotein [21-27]. The results of the present study were different that from those previous studies. In previous studies, the participants were not all long-lived subjects, but in the present, all participants were Nonagenarians/Centenarians. Longevity was multifactorial consequence, including genetic and environment factors. Genetic factors, which related with longevity, might include lipid metabolism gene, or include the gene, which could ant-disadvantage of smoking [28-30]. The genetic factor of longevity might have the function ant- disadvantage of smoking, including the effect of smoking on serum Lipid/Lipoprotein. This was also a reasonable inference, which should be further confirmed using experiment.

The present study showed that in long-lived subjects, smoking habits (current and former) were not associated with dyslipidemia, on the other hand, current smoker had lower TC and lower prevalence of abnormal TC. It had been confirmed that smoking habits (current and former) were definite risk factors of dyslipidemia. Therefore, from the results of the study, it could not conduct that in longlived subjects smoking habits (current and former) were not risk factors for dyslipidemia, or that smoking habits (current and former) were prophylactic factors for dyslipidemia. As explanation above, longevial genetic factors included which might have the function ant-disadvantage of smoking, including the effect of smoking on serum Lipid/Lipoprotein. These genetic factors were still unknown, and it might be a field of research on Longevity.

Our study had some limitations that deserve a mention. First, 870 subjects aged 90 years or older volunteered for the PLAD Study, among these 870 volunteers, only 661 had non-missing data for the two main variables involved in the current analyses. There might be selection biases. Second, because of the cross-sectional nature of this study, we only concluded the association between smoking habits and serum Lipid/Lipoprotein. We could not conduct causal conclusions on it. Third, since this is a part of the PLAD, there might be a survival bias. However, this is inherent in a study of individuals of this age group. Forth, because of the cross-sectional nature of this study, the subjects might change their diets and the conditions related to elevated serum lipid concentrations. However, the lifestyles and food habits of the nonagenarians/centenarians were relatively stable and similar. Fifth, inflammation seems to be the mediator of most of the issues related to chronic disease. It would help provide some insight rather than just speculating. However, the data were all from a survey conducted in 2005, the data could not included inflammatory factor. Finally, there subjects with smoking habits in men had more than those in women. Gender might influence the association of smoking habits with serum Lipid/Lipoprotein. Data analyzed according to gender might remove the influence. There only 661 participants, we analyzed data according to gender, none of the serum Lipid/Lipoprotein among different smoking habits had significant different, so this caused the sample size too small and could not obtain a conclusion. Therefore, we reported results using the total sample, not according to gender.

In conclusion, among longevity Chinese, only current smoking was related with low TC levels. But the smoking habits were not associated with the other serum Lipid/Lipoprotein. The relationship between smoking habits and serum Lipid/Lipoprotein in long-lived subjects was different from that in general adults. 


\section{Competing interests}

The author(s) declare that they have no competing interests.

\section{Acknowledgements}

This work was supported by the Discipline Construction Foundation of Sichuan University, and by grants from the Project of Science and Technology Bureau of Sichuan Province (2006Z09-006-4), and the Construction Fund for Subjects of West China Hospital of Sichuan University (XK05001). The authors thank the staff of the Department of Geriatrics Medicine, West China Hos-pital and Dujiangyan Hospital, and all participants (as well as their legal proxies) for their great contribution.

\section{Authors contribution}

BR Dong provided the funds and the design of this study. YL Zhang drafted the manuscript, performed the study and offered the payment for publication. DQ Zhao carried out modifying the article and data analysis. CQ Huang participated in the laboratory test. All authors read and approved the final manuscript.

Received: 13 April 2012 Accepted: 27 June 2012

Published: 24 July 2012

\section{References}

1. Craig WY, Palomaki GE, Haddow JE: Cigarette smoking and serum lipid and lipoprotein concentrations: an analysis of published data. BMJ 1989, 298:784-788.

2. Wang $S, X u L$, Jonas JB, You QS, Wang YX, Yang H: Prevalence and associated factors of dyslipidemia in the adult Chinese population. PLoS One 2011, 6:e17326.

3. Chelland Campbell S, Moffatt RJ, Stamford BA: Smoking and smoking cessation -- the relationship between cardiovascular disease and lipoprotein metabolism: a review. Atherosclerosis 2008, 201:225-235.

4. Maeda K, Noguchi Y, Fukui T: The effects of cessation from cigarette smoking on the lipid and lipoprotein profiles: a meta-analysis. Prev Med 2003, 37:283-290.

5. Lee MH, Ahn SV, Hur NW, Choi DP, Kim HC, Suh I: Gender differences in the association between smoking and dyslipidemia: 2005 Korean National Health and Nutrition Examination Survey. Clin Chim Acta 2011, 412:1600-1605.

6. Tseng CH, Tseng CP, Chong CK: Joint effects of hypertension, smoking, dyslipidemia and obesity and angiotensin-converting enzyme DD genotype on albuminuria in Taiwanese patients with type 2 diabetes mellitus. Clin Biochem 2010, 43:629-634.

7. Onat A, Ayhan E, Hergenç G, Can G, Barlan MM: Smoking inhibits visceral fat accumulation in Turkish women: relation of visceral fat and body fat mass to atherogenic dyslipidemia, inflammatory markers, insulin resistance, and blood pressure. Metabolism 2009, 58:963-970.

8. Tan XJ, Jiao GP, Ren YJ, Gao XR, Ding Y, Wang XR, Xu H: Relationship between smoking and dyslipidemia in western Chinese elderly males. J Clin Lab Anal 2008, 22(3):159-163.

9. Huang $C Q$, Dong BR, Zhang YL, Wu HM, Liu QX: Association of cognitive impairment with smoking, alcohol consumption, tea consumption, and exercise among Chinese nonagenarians/centenarians. Cogn Behav Neurol 2009, 22:190-196.

10. Ji-Rong Y, Bi-Rong D, Chang-Quan H, Yan-Ling Z: Depression and serum lipids and lipoprotein in Chinese nonagenarians and centenarians. J Am Geriatr Soc 2009, 57:732-733.

11. Huang CQ, Dong BR, Wu HM, Zhang YL, Wu JH, Lu ZC, Flaherty JH: Association of cognitive impairment with serum lipid/lipoprotein among Chinese nonagenarians and centenarians. Dement Geriatr Cogn Disord 2009, 27:111-116.

12. Margolis CF, Sprecher DL, Simbartl LA, Campaigne BN: Male-female differences in the relationship between obesity and lipids/lipoproteins. Int J Obes Relat Metab Disord 1996, 20(8):784-790.

13. Bartelt A, Bruns OT, Reimer $R$, Hohenberg H, Ittrich $H$, et al: Brown adipose tissue activity controls triglyceride clearance. Nat Med 2011, 17:200-205.

14. Aubree-Lecat A, Hervagault C, Delacour A, Beaude P, Bourdillon C, Remy M: Direct electrochemical determination of glucose oxidase in biological samples. Anal Biochem 1989, 178:427-430.
15. Sun YH, Pei WD, Wu YJ, Wang GG: Association of herpes simplex virus type2 infection with dyslipidemia in Chinese. Zhonghua Yi Xue Za Zhi 2003, 83(20):1774-1777.

16. Juan D, Zhou DH, Li J, Wang JY, Gao C, Chen M: A 2-year follow-up study of cigarette smoking and risk of dementia. Eur J Neurol 2004, 11:277-282.

17. Tyas $S L$, White $L R$, Petrovitch $H$, et al: Mid-life smoking and latelife dementia: the Honolulu-Asia aging study. Neurobiol Aging 2003, 24:589-596.

18. Knezevic T, Denic L, Radovic L: Smoking habits of employees in public-health institutes. Cah Sociol Demogr Med 2010, 50(3):361-373.

19. Farzadfar F, Danaei G, Namdaritabar H, Rajaratnam JK, Marcus JR, Khosravi A, Alikhani S, Murray CJ, Ezzati M: National and subnational mortality effects of metabolic risk factors and smoking in Iran: a comparative risk assessment. Popul Health Metrics 2011, 9:55.

20. Halmenschlager G, Rossetto S, Lara GM, Rhoden EL: Evaluation of the effects of cigarette smoking on testosterone levels in adult men. J Sex Med 2009, 6:1763-1772.

21. Nakamura K, Barzi F, Huxley R, Lam TH, Suh I, Woo J, Kim HC, Feigin VL, Gu D, Woodward M, Asia Pacific Cohort Studies Collaboration: Does cigarette smoking exacerbate the effect of total cholesterol and high-density lipoprotein cholesterol on the risk of cardiovascular diseases? Heart 2009, 95:909-916.

22. Tuomilehto J, Tanskanen A, Salonen JT, Nissinen A, Koskela K: Effects of smoking and stopping smoking on serum high-density lipoprotein cholesterol levels in a representative population sample. Prev Med 1986, 15:35-45.

23. Freedman DS, Serdula MK, Percy CA, Ballew C, White L: Obesity, levels of lipids and glucose, and smoking among Navajo adolescents. J Nutr 1997, 127:2120S-2127S.

24. Jee SH, Suh I, Kim IS, Appel LJ: Smoking and atherosclerotic cardiovascular disease in men with low levels of serum cholesterol: the Korea Medical Insurance Corporation Study. JAMA 1999, 282:2149-2155.

25. Schuitemaker GE, Dinant GJ, van der Pol GA, van Wersch JW: Relationship between smoking habits and low-density lipoprotein-cholesterol, high-density lipoprotein-cholesterol, and triglycerides in a hypercholesterolemic adult cohort, in relation to gender and age. Clin Exp Med 2002, 2:83-88.

26. Uno F, Ishikawa S, Nakamura Y, Gotoh T, Nago N, Kayaba K, Kajii E: Smoking and risk of all-cause mortality: the Jichi Medical School (JMS) cohort study. J Epidemiol 2005, 15:173-179

27. Hozawa A, Okamura T, Kadowaki T, Murakami Y, Nakamura K, Hayakawa T, Kita Y, Nakamura Y, Okayama A: Hirotsugu Ueshima for NIPPON DATA80 Research group.ls weak association between cigarette smoking and cardiovascular disease mortality observed in Japan explained by low total cholesterol? NIPPON DATA80. Int J Epidemiol 2007, 36:1060-1067.

28. Conde-Pérezprina JC, Luna-López A, González-Puertos WY, Zenteno-Savín T, León-Galván MA, Königsberg M: DNA MMR systems, microsatellite instability and antioxidant activity variations in two species of wild bats: Myotis velifer and Desmodus rotundus, as possible factors associated with longevity. Age (Dordr) 2012, [Epub ahead of print].

29. Kaufman SR, Fjord L: Medicare, ethics, and reflexive longevity: governing time and treatment in an aging society. Med Anthropol Q 2011, 25:209-31.

30. Mouchiroud L, Molin L, Dallière N, Solari F: Biofactors. Life span extension by resveratrol, rapamycin, and metformin: the promise of dietary restriction mimetics for an healthy aging. Age 2010, 36:377-382.

\section{doi:10.1186/1476-511X-11-94}

Cite this article as: Yan-Ling et al.: Cigarette smoking and its association with serum lipid/lipoprotein among Chinese nonagenarians/ centenarians. Lipids in Health and Disease 2012 11:94. 